\title{
The Danube Region-On Stream with Animal Welfare Assessment in the Last 35 Years: A Review of Research on Animal Welfare Assessment in a Multi-lingual Area in Europe
}

\author{
Tomislav Mikuš ${ }^{1}$ (D) Miroslav Radeski ${ }^{2}$ - Ludovic Toma Cziszter ${ }^{3}$. \\ Ivan Dimitrov $^{4}$ - Viktor Jurkovich ${ }^{5}$ Katarina Nenadović ${ }^{6}$ • \\ Mario Ostović ${ }^{7} \cdot$ Manja Zupan $^{8} \cdot$ Marlene Katharina Kirchner9 $^{9}$
}

Accepted: 30 May 2018/Published online: 8 June 2018

(C) The Author(s) 2018

\begin{abstract}
This review presents first ever literature survey on historical development of farm animal welfare indicators and assessment in the Danube region. This area, encompassing European Eastern countries and the Balkans, is to a large extent heterogeneous in terms of culture and language. However, international (English) publications were disproportionally small compared to the amount of research institutions and animal welfare activities present in the region. Therefore, the authors aimed at investigating the published literature, focusing on country level and on native languages. Data were collected for the 1980-2015 period referring to scientific papers published in international and national journals, papers and
\end{abstract}

Tomislav Mikuš
mikus@ veinst.hr
Miroslav Radeski
miro@fvm.ukim.edu.mk
Ludovic Toma Cziszter
cziszterl@animalsci-tm.ro
Ivan Dimitrov
iv.dimitrov@dir.bg
Viktor Jurkovich
Jurkovich.Viktor@univet.hu
Katarina Nenadović
katarinar@vet.bg.ac.rs
Mario Ostović
mostovic@vef.hr
Manja Zupan
manja.zupan@bf.uni-lj.si
Marlene Katharina Kirchner
mk@sund.ku.dk
Animal Welfare Office, Croatian Veterinary Institute, Savska cesta 143, 10000 Zagreb, Croatia 
abstracts in proceedings of the international and national conferences, reviews, monographs, short communications, Ph.D., Master and Graduation theses. Welfare assessment of all farm animal species was observed including fish. Over 180 papers were in line with the preselected index. Data collected showed that publishing dynamics grew rapidly towards the last decade. Most of the studies were focused on animal welfare indicators such as stress, injuries and mutilations, behaviour, body condition and management practices. Cattle, chickens, pigs and sheep were the predominant species investigated. The study revealed that experts from the region were greatly involved in the studies of animal welfare indicators and assessment, contributing to development of the currently most widely used animal welfare assessment protocols, thus having an important role in animal welfare research and protection.

Keywords Danube region - Animal welfare - Indicator - Assessment - Historical development $\cdot$ Review

\section{Introduction}

Animal welfare research, as such, is a relatively young field of science that combines multiple scientific disciplines with constant motivation to better understand how animals experience their world, and how humans affect them. Understanding of animals and their behaviour is getting ever more complex involving multidisciplinary studies in the fields of natural and social sciences related to animal husbandry and human-animal interactions (Lund et al. 2006; Carenzi and Verga 2009). Regarding its historical development, animal welfare as a 'formal discipline' started with publications such as "Animal machines" by Harrison (1964) and Brambell report on the welfare of farm animals, issued by the British

2 Faculty of Veterinary Medicine, Animal Welfare Centre, Ss Cyril and Methodius University, Lazar Pop-Trajkov 5-7, 1000 Skopje, Macedonia

3 Faculty of Animal Science and Biotechnology, Banat's University of Agricultural Sciences and Veterinary Medicine "King Michael I of Romania”, Calea Aradului 119, 300645 Timisoara, Romania

4 Agricultural Institute, NIGO, 6000 Stara Zagora, Bulgaria

5 Department of Animal Hygiene, Herd Health and Veterinary Ethology, University of Veterinary Medicine, Istvánutca 2, 1078 Budapest, Hungary

6 Faculty of Veterinary Medicine, Department of Animal Hygiene, University of Belgrade, Bulevar oslobođenja 18, 11000 Belgrade, Serbia

7 Faculty of Veterinary Medicine, Department of Animal Hygiene, Behaviour and Welfare, University of Zagreb, Heinzelova 55, 10000 Zagreb, Croatia

8 Biotechnical Faculty, Department of Animal Science, University of Ljubljana, Groblje 3, 1230 Domžale, Slovenia

9 Department of Veterinary and Animal Sciences, Institute of Animal Welfare and Disease Control, University of Copenhagen, Grønnegårdsvej 8, 1870 Frederiksberg C, Denmark 
government in 1965 (Brambell Report 1965). Adoption of a conventional scientific approach, with experiments focusing on the effects of single factors under controlled conditions, allowed the new discipline to be established as a science, or as "a young science" (Sandøe et al. 2003; Millman et al. 2004).

Moreover, during the last 40 years, the concept of animal welfare has evolved from focusing primarily on animal physical health and ability to cope (Broom 1988) to recognising animals as sentient beings, capable of experiencing positive and negative emotions (Duncan 2006). The social and ethical dimensions of animal welfare, which are concerned with how human society morally regards and treats non-human animals, are also increasingly being recognised (Fraser et al. 1997; Sandøe et al. 2003). Furthermore, there is a growing effort worldwide developing objective indicators for animal welfare assessment, which should provide information on the animal quality of life (valid), be scientifically trustworthy (reliable), and readily usable in practice by professionals (feasible) (Wemelsfelder and Mullan 2014). A very large amount of studies have been conducted regarding development of animal welfare assessment methods in different production systems and farmed species, as well as the answers to fundamental questions related to the biological bases of welfare and stress. The application of animal welfare indicators and assessment protocols has been investigated predominantly in farm animals. Early studies on welfare assessment at the farm level focused mostly on 'inputs' to animal welfare, i.e. 'environmentally-based measures' (e.g., husbandry, management resources) (Bartussek 1999). However, in the last 20 years, there has been increasing interest in assessing welfare 'outcomes'-how these resources actually affect animal welfare. By observing animals in different husbandry systems, we can assess their health and welfare more directly and in greater detail, using so called 'animal-based-measures' (Whay et al. 2003). As animal welfare was found to be better pictured by multi-criteria approach, various protocols have been developed recently aiming to provide a more holistic welfare assessment of animals on farms. This becomes evident as they are integrating the range of indicators into an overall welfare score or category (Botreau et al. 2009), the best known being the Welfare Quality protocols (Blokhuis et al. 2010). Recent research in Europe is therefore encompassing closer investigation of single indicators suitable for defining substantial aspects of animal welfare, or aiming at accomplishing meaningful compositions and aggregations of those single indicators into assessment protocols. In this review, studies with both approaches are presented, showing animal welfare research activities in the last 35 years in the Danube region, encompassing countries from Eastern Europe and the Balkans.

Europe has been, and remains, a global leader in the development of animal welfare policies. Yet, it has a great diversity of cultures and religions, different levels of socio-economic development, and varied legislation, policies and practices. Nevertheless, there are common drivers for animal welfare policy based on the history of animal welfare ethics and obligations to animal users and society in general. Ethics is the overarching driver, supported by governmental, intergovernmental and non-governmental activities, markets and trade, science and knowledge (Dalla Villa et al. 2014). With regard to this, the "Danube region" was an interesting subject to investigate development of animal welfare assessment 
strategies and research. The Danube region is a geographical and political region stretching from south Germany across Austria, Slovenia, Hungary, Croatia and Serbia towards Bulgaria, Romania, Moldova and south Ukraine. It is a region that was facing great social and political dynamics in the last 50 years, even more in the last 20 years. In all of the Danube region countries, language is more or less distinct and cultural differences were forming the countries with remaining minorities in many cases. From earlier EU-funded studies such as AWARE (2013), it was already known that farm animal research did not develop evenly across the enlarged Europe, and was also influenced by economic situation of the countries in the Eastern region. In this region, the universities and research institutions investigating the field of animal welfare science were primarily financed by their governments (Kirchner et al. 2017). This could lead to the assumption that they were serving primarily national duties and autochthonous challenges in the veterinary and agricultural fields. Furthermore, this national funding implies that the outcomes of the studies and published papers were mostly written in local languages and published in the national journals or conference proceedings. Assumingly, the language barrier and a lack of external, international funding hampered visibility of papers from the Danube region to the international scientific community, which was addressed in coordination projects such as AWARE (2013). Accordingly, it would be essential to search for literature of the Danube region in the respective native languages to arrive at a comprehensive summary of the research on animal welfare assessment performed.

In order to perform a holistic review of the area, a specific strategy of this study was therefore to collect all available scientific literature from the Danube region, reflecting on the one published in regional languages on the topic of animal welfare indicators/assessment. The overall aim was not only to explore the amount of publications in the field, but to focus on the most frequent animal welfare assessment indicators or assessment systems and species in the scientific literature from the Danube region in the past $30+$ years.

\section{Methodology}

\section{Approach in Finding Autochthonous Literature}

To actually get an idea on the amount of research on animal welfare assessment done and published in the Danube region, the authors as native researchers planned to collect the papers from their own countries (Fig. 1), covering in total data from eight countries of the wider Danube region (including Macedonia). Not all countries of the Danube region were included, as some invited colleagues could not respond in time, and data could not be found for some countries such as Bosnia and Herzegovina, Montenegro, and Kosovo. Data from Macedonia were also included in the database although this country is not part of the Danube region, but scientific researchers from this country were in the region in the past, in former Yugoslavia. Similarities among countries in the region are presented in: (a) traditional farming model (family farms), which grew rapidly to large agglomerations in the period of 


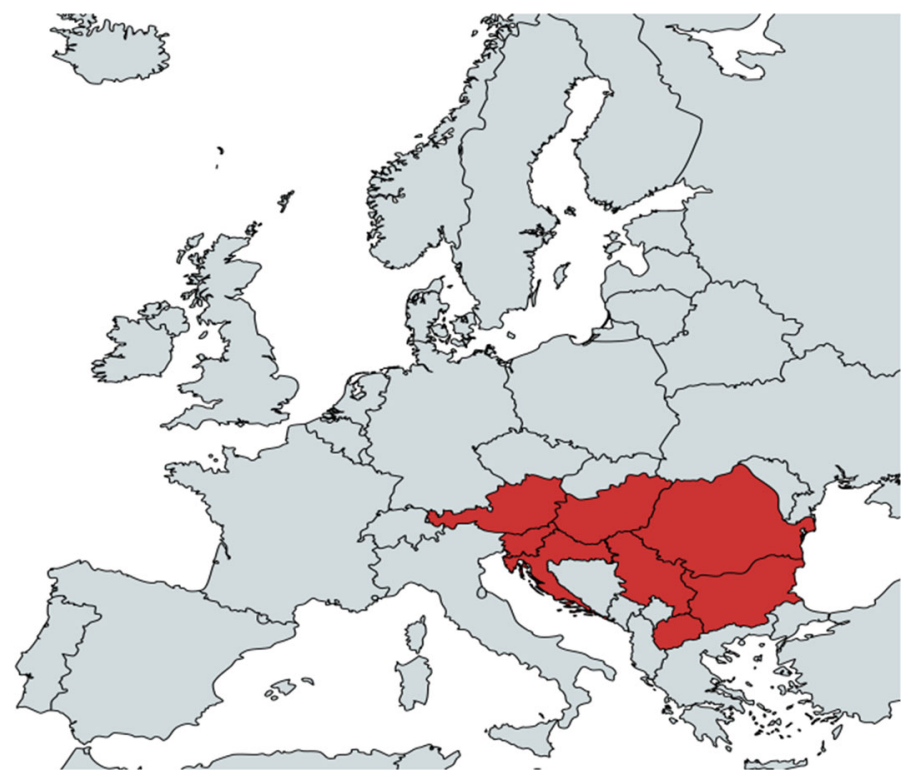

Fig. 1 Countries included in the review

socialism, (b) historical influence of the same "veterinary schools", (c) language similarities (German and Slavic base with the exception of Hungary and Romania), (d) cultural heritage, and (e) continuous human migration across the region. Because of the similarities, research conducted in the countries observed should be applicable to the wider Danube region.

\section{Literature Research and Search Criteria}

Data were collected from June 2015 to April 2016 by searching papers in the international and national scientific journal bases, and university and faculty libraries across the Danube region in the following categories: scientific papers in the international journals, scientific papers in the national (local) journals, papers and abstracts in the proceedings of international conferences, papers and abstracts in the proceedings of national conferences, reviews, monographs, short communications, $\mathrm{PhD}$ theses, Master theses and Graduation theses.

Keywords were preselected by focusing on the Welfare Quality protocol assessment criteria, but also taking into account historical development of some terms. Throughout the history, different terms were used for the same animal welfare indicators at the international level, including the Danube region. Therefore, on data collection, key words were selected as shown in Table 1. The selected keywords were then translated and adapted to all regional languages, which allowed us to use a greater source of data in paper search.

The review focused on all farm animal species (cattle, chicken, duck, fish, goat, horse, pig, rabbit, sheep and turkey). Several papers were dealing with more than one species and they were selected as "multiple species" papers (Fig. 2). 
Table 1 Preselected key words and short description of the terms

Welfare indicator-key word Description

Animal welfare assessment protocol

Animal hygiene/Zoohygiene

Prolonged hunger

Prolonged thirst

Comfort around resting

Thermal comfort

Movement

Injuries

Disease

Pain

Behaviour

Human-animal relationship/ animal handling

Animal emotional state
All protocols used for animal welfare assessment in the species observed

Throughout the history, this term was used frequently for some aspects of animal welfare

Hunger in relation to animal welfare

Thirst in relation to animal welfare

Lying area, type of flooring, housing equipment, lying down movements, getting up behaviour, cleanliness

Signs (behaviours) of too high or too low temperatures

Access to pasture, outdoor runs, tethering, ease of movement, space allowance

Injuries caused by inappropriate treatment of the animal, housing conditions, management procedures

Disease as an animal welfare indicator

Pain induced by all causes related to animal housing and management (mutilations, painful treatment)

Animal behaviour in the context of animal welfare, behaviour assessment under different conditions; normal and abnormal behaviours in the species observed, etc.

Human-animal relationship testing, indicators of animal handlingpositive or negative

Indicators of animal emotional state-positive or negative

(n)

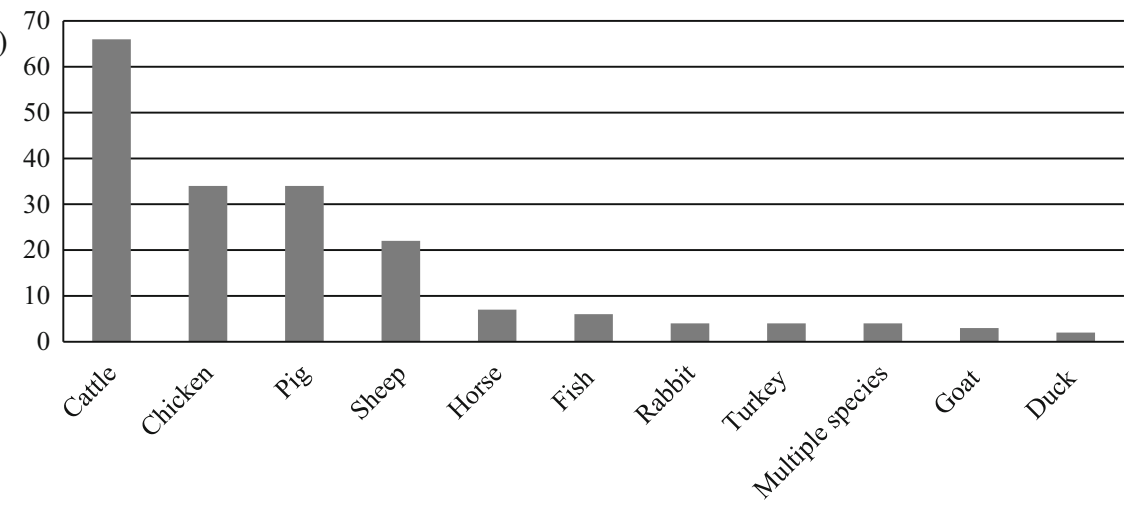

Fig. 2 Identified publications according to animal species

\section{Selection Criteria of Papers for the Review}

The data collected with the above-mentioned approach revealed 497 papers; descriptive data on these were published previously (Radeski et al. 2016) and are not shown in this review. The generated database is available on request from the 
authors. Due to a large number of papers found, hereby we outlined just a fragment of them with a specific accent on topics, indicators, timeframe and species. According to the study, it has become obvious that before 1980 there were almost no papers on the topic of animal welfare assessment development in the Danube region. Therefore, the selected time frame for this review was scheduled from 1980 and completed in 2015. Moreover, data were divided according to decades: 1980-1989, 1990-1999, 2000-2009 and 2010-2015.

Further paper selection was based on the paper contents and whether papers where actually in line with the topic of animal welfare assessment development. Finally, the remaining papers $(n=186)$ could be grouped into following three major categories: single indicators, assessment systems and species specialties of the region, which is presented in the next chapter.

\section{Results}

\section{Identified Topics and Indicators}

Early studies in the Danube region mostly focused on stress caused by unsuitable feed intake and farm management and its repercussions for the animal (Kovačević 1981; Madjirov 1981; Madjirov and Tokovski 1984). The authors also argued about the importance of animal welfare assessment in intensive production (Hristov 1989). By the end of 1990, the final version of Animal Needs Index (ANI) was published (Bartussek 1990). The ANI system is well known and laid down a significant foundation to further development of animal welfare assessment protocols. In general, five measures were identified by the ANI: freedom of movement, flooring, social contacts, light and air conditions, and intensity of care. For all of these measures, minimum requirements had to be fulfilled.

Development of indicators that could be used in the welfare assessment throughout the 1990s had several trends. Firstly, authors investigated behavioural changes in animals regarding their temperament (Dimitrov-Ivanov and Djorbineva 1998, 1999). Furthermore, they measured biochemical indicators in blood, such as cortisol (Hristov et al. 1994, 1996; Pavičić 1997). Finally, Waiblinger et al. (2001) proposed to undertake epidemiological study and to use multivariate analysis in order to develop assessment models relating to particular aspects of animal welfare.

At the beginning of the new millennium, the number of papers on animal welfare assessment in the Danube region grew rapidly, and with the increasing number of papers there were new areas appearing in the focus of researchers. Although the ANI system was developed, authors in the region were focusing on development of individual indicators for animal welfare assessment such as:

1. Injuries and mutilations Gasteiner and Hochsteiner (2001) assessed leg health and skin lesions in dairy cows in different housing systems (loose, tied, littered and slatted). The results of their study showed that up to $70 \%$ of animals had some sort of leg disorder, and up to $8 \%$ of animals had skin lesions. Investigating rabbit preferences for cages of various heights, their production 
and occurrence of ear lesions, Princz et al. (2008) found the commonly used $30-35 \mathrm{~cm}$ high cages to be satisfactory for growing rabbits. The frequency of ear lesions associated with aggressive behaviour was lowest in $30 \mathrm{~cm}$ and highest in $20 \mathrm{~cm}$ high cages. There was no influence of cage height on rabbit production. Ostović et al. (2009) pointed out issues regarding animal welfare in intensive turkey rearing systems-poor comfort due to high stocking density, prolonged hunger as a subsequence of restrictive feeding programs, and routine mutilation procedures. These authors emphasised the need of modification of certain production practices, as well as of environmental enrichment in intensive turkey production

2. Behaviour Zupan et al. (2003) investigated differences among broiler chickens in three different rearing systems. The behaviour of broilers reared in the floor system was most passive, while comparing free range and organic system yielded small differences in broiler behaviour. Petak (2006) conducted a study on the effect of two natural preparations, probiotic Ascogen ${ }^{\circledR}$ and immunomodulatory Baypamun ${ }^{\circledR}$, on boar behaviour and welfare during summertime because, as the author explained, boar welfare is compromised at that time of the year. She also investigated the boar reproduction successfulness due to high temperatures. Although the author concludes with recommendation for use of natural preparations, she also emphasizes that the focus of industry needs to be on other solutions such as upgrading the pen with enriched materials so that boars could express their normal behaviour.

Nikolov (2005) compared feeding behaviour in cows with free access to alfalfa hay and restricted access to green maize. The time of consuming the preferred forage depended on the individual preferences and on the hierarchy in the herd. When restricted, the animals occupying lower position in the hierarchy were waiting for free access to it, thus the time of feeding decreased and they remained undernourished. Gavojdian et al. (2009) assessed dairy cow resting behaviour in tie-stall during winter and summer seasons. Cows were monitored in their first hundred days of lactation. The results of the study showed that the time spent resting in winter months was significantly longer than the time devoted to rest during summer months.

3. Body condition score Šamanc et al. (2006, 2007a, b) published several papers on the body condition of dairy cows, sows and calves with regard to production stage, body postures, and prolonged hunger and thirst.

5. Management practices Gutzmirtl (2008) investigated sow welfare in two different housing systems, on a farm with industrial housing of sows and on a family farm where sows were kept freely. A higher concentration of cortisol was recorded 5 days before farrowing, after animals were transferred to farrowing crates, in sows previously housed free compared with sows housed industrially. The author concluded that higher concentration of cortisol in sows kept freely was a repercussion of stress induced by moving animals to the new environment and limited space of farrowing crates. Hristov et al. (2008) pointed out that all buildings and housing systems for dairy cattle should be so designed, constructed, maintained and managed as to assist in the achievement of the Five Freedoms. Whether dairy cows are housed in cubicles, straw yards or cow 
sheds, the accommodation must ensure animal basic behavioural and physiological needs in order to maximize their performance and provide satisfactory welfare standards.

\section{Development of Animal Welfare Assessment Systems}

Except for the development of individual indicators, several authors emphasised the necessity of developing the overall welfare assessment protocol. Ofner et al. (2003) pointed to the increasing demands for suitable systems for the assessment of animal welfare, exemplifying it by the wide use of ANI in Austria. The authors focused on the validity of ANI assessment, and explored the correlation between animal welfare as assessed by the ANI system with several other animal health and behavioural parameters. The results obtained showed significant correlations between ANI scores and animal behaviour and health parameters such as skin lesions and injuries. This indicated good assessment validity of the ANI system in cattle and confirmed that ANI is a feasible and reliable tool for animal welfare assessment on farms. Furthermore, the authors conclude that comprehensive system for on-farm animal welfare assessment must comprise parameters of housing, climate, management and stockmanship, and animal-based parameters. Winckler et al. (2003) focused on the selection of parameters for cattle and buffalo from welfare research, assessment protocols used in different European countries, and from the literature. The authors describe three groups of parameters: (1) parameters which can be included in assessment protocols, such as lameness, injuries, body condition score, cleanliness, getting up/lying down behaviour, agonistic social behaviour, oral abnormal behaviours, human behaviour toward the animals, and measures of the animal-human relationship; (2) parameters which require more information on reliability, such as housing factors; and (3) parameters which are regarded as important but so far lack reliability in most countries, such as the incidence of clinical diseases and mortality.

\section{Implementation of Existing Animal Welfare Assessment Protocols}

Review papers on the existing protocols were published by several authors from the region. Zaludik et al. (2007) compared ANI data derived from annual inspections by a control agency with data collected from selected on-farm flocks regarding feather damage, injuries, egg production, mortality, body weight, footpad dermatitis, keel bone deviations and reactions towards humans. They conclude that welfare-related animal-based parameters are poorly reflected by the ANI system. In addition, for more adequate animal welfare assessment, animal-based parameters also have to be considered. Cziszter et al. (2009) reviewed animal welfare assessment with reference to calves. Assessment methods in general were divided into assessment protocols at individual level and those at farm (group) level. At the farm level, the ANI 35L system was discussed and the ANSVSA Romanian evaluation form was presented. The EFSA (2006) opinion on poor welfare in intensive calf farming systems was also presented in this paper. 
In the recent 5 years (2010-2015), studies were mostly based on applying the Welfare Quality protocol throughout the region (Popescu et al. 2011; Jurkovich et al. 2012; Vučemilo et al. 2012; Kirchner et al. 2014; Radeski et al. 2014), and further research on the other possible animal welfare indicators which are not included in this protocol. The heart rate variability in dairy cows as a possible indicator was investigated in several contexts, such as during milking (Kovács et al. 2013) or during a possible painful veterinary procedure, rectal palpation (Kovács et al. 2014), or related to housing and other parameters (Kovács et al. 2015). Dimitrov et al. (2012) assessed the welfare of sheep using a holistic emotion approach. This particular study emphasised assessment of emotional processes in sheep of different temperaments tracing in this way the opportunity to experiment on animals predisposed to express more positive or negative affective states.

\section{What About Species?}

The species-wise regional activity did not change much during the 1980-2015 period. Most of the studies were done on cattle, chickens, pigs and sheep (Fig. 2).

Studies regarding the welfare assessment protocol for cattle have been under development since the 1980s, and the need for such a protocol has been stressed by several authors in the region (Hristov 1989; Bartussek 1990). Hristov (1989) pointed out the importance of assessing adaptation of newborn calves in intensive production.

Although pigs have also been studied from the beginning of the 1980s (Madjirov 1981), most of the studies considered only one parameter and its influence on pig productivity (Šarac 1991; Hristov et al. 1996). Development of welfare protocol for pigs (sows in this case) was presented by Andronie et al. (2010). The aim of their study was to assess the welfare of pregnant sows housed in group pens, based on the indicators such as behaviour, skin lesions and lameness, and the authors concluded that the welfare of pregnant sows should be evaluated using different criteria depending on breeding technology. Ostović (2012) investigated the effect of rubber mats on the welfare of gilts housed individually in service unit. He concluded that the use of rubber flooring had a positive effect on gilt welfare during cold months considering lower lesion score and reduction in stress level, as well as lower display of stereotypies and improved lying comfort.

An interesting fact is disproportion of studies regarding sheep and goats. Although both of the species are very traditional for the region, sheep were seven times more studied than goats. Different aspects of sheep welfare have been intensively investigated since the end of 1990s (Dimitrov-Ivanov and Djorbineva 1998, 1999; Gudev et al. 2007; Radeski and Ilieski 2014), while a comprehensive study on dairy goat welfare and influencing factors was presented only recently by Waiblinger et al. (2014).

Popescu et al. (2012) conducted a study on riding horses concerning their ability to cope with the challenges of their environment using physiological indicators such as heart rate, respiratory rate and rectal temperature. The physiological indicators were determined by two batches of testing, in different environmental conditions. The authors conclude that physiological indicators tested in this study proved their 
real value in the riding horse welfare assessment, and that a relatively simple and quick health check may show a significant dimension of the riding horse welfare.

Szendro et al. (2013) investigated differences between single and group housing of wild rabbits in Hungary as an interventional study proposed by the Animal Protection Group, and concluded that group housing was not recommended because of high stress, increased mortality and morbidity, and low productivity, i.e. poorer animal welfare and increased production costs.

Matković et al. (2007) reviewed alternative housing systems for laying hens in four different European countries and Croatian legislation. The authors conclude that while the transition to the alternative housing system can be a challenge, satisfaction with achievements and the balance between animal welfare and successful production can be an extraordinary reward. They also add that although high productivity, low mortality and safe working environment are achievable, the management of these systems requires significant effort and skills, which must be developed throughout experience.

Studies on the fish welfare were not so popular until the last few years. The first research conducted in the region was done by Hristovski and Cvetkovic (2005) regarding behaviour and consequences of stress in extensive aquaculture in warm water fish farms. Veljačić and Tofant (2009) reviewed the fish welfare, describing the physiological and behavioural indicators. They also argued about the factors influencing the welfare of fish in intensive production, such as stocking density, feeding, transport, stunning, and quantity and quality of water. Relić et al. (2010) provided a thorough review of available welfare assessment indicators of fish welfare emphasising the non-invasive assessment techniques such as monitoring of behaviour, and point out that a unique system of welfare assessment has not yet been defined.

\section{Discussion}

\section{Regional Development of Animal Welfare Assessment}

The small number of papers in the Danube region in the 1980s was somewhat expected due to the novelty of the topic. Yet, the high number of papers and diversity of topics in the last 15 years was quite surprising. The factors most likely contributing to this finding were as follows: (1) political (re)evolution; (2) expert integration in EU funded projects; and (3) motivation of regional scientists to cover the "uncharted territory".

Political (re)evolution in the Danube region started in the last two decades of the 20th century and had significant impact on all parts of the society. Change in the region political structure fielded the need for countries to join the EU. During the accession procedure, the countries developed and/or harmonised legislation on animal protection and welfare. Most of the countries in the Danube region became EU members in the 2000s. Direct outcome of this political evolution was integration of regional experts in the EU funded projects. Projects such as AWARE, which had a goal to promote integration and increase the impact of European research on farm 
animal welfare through development of Europe-wide networks of scientists, lecturers and students included a great number of regional scientists and developed a regional network (AWARE 2013). Besides AWARE, there have been several regional projects aiming to develop and support animal welfare development in the region, such as Western Balkan Veterinary Network for Animal Welfare-WBVN (Hammond Seaman 2014) and Regional Animal Welfare Centre-RAWC (Petkova and Hammond Seaman 2017). Both of these projects have been integrating different methods in the animal welfare assessment trainings in the region for the last 10 and more years. With all these political and scientific initiatives, it was not surprising that scientists from the region were motivated to study in the "uncharted territory" of animal welfare.

\section{Interconnection with Western European Animal Welfare Initiatives}

This study showed that most of the studies and papers published in the last three and a half decades in the Danube region regarding animal welfare assessment were greatly interconnected with internationally recognized papers. Several ideas were first developed in the Danube region (e.g., ANI system), and stakeholders from the region also had an integrated role in the development of advanced animal welfare assessment systems such as Welfare Quality (Blokhuis et al. 2010) and AWIN (AWIN 2015). Besides these internationally recognised contributionsof the region experts in the animal welfare assessment development, there were several more papers in line with Western European animal welfare initiatives of the time, or even ahead of time. For example, Dimitrov-Ivanov and Djorbineva (1998) published a method for assessing temperament in dairy sheep, and in the years to come these authors published six more papers on similar topics with more developed tests for scaling sheep into groups based on different behavioural, cortisol and immune responses. An overall international animal welfare assessment protocol for sheep has been published just recently, in 2015, as an outcome of the AWIN project (AWIN 2015).

\section{Conclusions}

Development of animal welfare indicators and assessment protocols in the Danube region is presented in this review. According to the data collected, publishing dynamics grew rapidly from 1980 to 2015 . The most investigated indicators in the region referred to stress, injuries and mutilations, behaviour, body condition, and management practices, with cattle, chickens, pigs and sheep as the most studied species. There werea vast number of national papers concerning animal welfare indicators and assessment, and animal welfare in general in the region. Accordingly, this review proves that the Danube region has been very active in the studies of animal welfare indicators and assessment protocol development during the last 35 years, and provides a good database for further animal welfare studies in the region and beyond. 
Open Access This article is distributed under the terms of the Creative Commons Attribution 4.0 International License (http://creativecommons.org/licenses/by/4.0/), which permits unrestricted use, distribution, and reproduction in any medium, provided you give appropriate credit to the original author(s) and the source, provide a link to the Creative Commons license, and indicate if changes were made.

\section{References}

Andronie, I., Pârvu, M., Andronie, V., \& Radu, A. (2010). The welfare of gestating sows in different housing. Animal Science and Biotechnologies, 43(2), 280-283.

AWARE. (2013). Report on the mapping of farm animal welfare research.pdf. http://www.aware-welfare. eu/aware/45962/5/0/60. Accessed October 11, 2017.

AWIN. (2015). AWIN welfare assessment protocol for sheep. http://www.animal-welfare-indicators.net/ site/flash/pdf/AWINProtocolSheep.pdf. Accessed October 20, 2017.

Bartussek, H. (1990). Der Tiergerechtheitsindex. Neue Agrarzeitung, 13, 5-6.

Bartussek, H. (1999). A review of the animal needs index (ANI) for the assessment of animals' wellbeing in the housing systems for Austrian proprietary products and legislation. Livestock Production Science, 61(2-3), 179-192.

Blokhuis, H. J., Veissier, I., Miele, M., \& Jones, B. (2010). The Welfare Quality ${ }^{\circledR}$ project and beyond: Safeguarding farm animal well-being. Acta Agriculturae Scandinavica, Section A: Animal Science, 60(3), 129-140.

Botreau, R., Veissier, I., \& Perny, P. (2009). Overall assessment of animal welfare: Strategy adopted in Welfare Quality ${ }^{\circledR}$. Animal Welfare, 18(4), 363-370.

Broom, D. M. (1988). The scientific assessment of animal welfare. Applied Animal Behaviour Science, 20(1-2), 5-19.

Carenzi, C., \& Verga, M. (2009). Animal welfare: Review of the scientific concept and definition. Italian Journal of Animal Science, 8(Suppl. 1), 21-30.

Cziszter, L. T., Stanciu, G., Acatincăi, S., Szucs, E., Erina, S., Tripon, I., et al. (2009). Methods for calf welfare evaluation. Lucrăriştiinţifice Zootehnieşi Biotehnologii, 42(2), 547-553.

Dalla Villa, P., Matthews, L. R., Alessandrini, B., Messori, S., \& Migliorati, G. (2014). Drivers for animal welfare policies in Europe. Revue Scientifique Et Technique-Office International Des Epizooties, 33(1), 39-46.

Dimitrov, I., Peeva, J., Sotirov, L., Tsoneva, V., Rassu, P. G., Mihaylova, M., et al. (2012). Assessing emotional processes in dairy sheep of different temperaments: Behavioural, cortisol and immune responses in dairy sheep experiencing positive and negative emotions on farm. In Proceedings of the 46th congress of the international society for applied ethology, 31 July-4th August 2012, Vienna, Austria (pp. 21-22).

Dimitrov-Ivanov, I., \& Djorbineva, M. (1998). A method for assessing the temperament in dairy sheep. In Proceedings of the 32nd congress of the international society for applied ethology, 21-25 July 1998, Clermont-Ferrand, France (pp. 167-168).

Dimitrov-Ivanov, I., \& Djorbineva, M. (1999). Assessment of fear reactions in dairy sheep and influence of temperament. In Proceedings of the 6th international symposium on the milking of small ruminants, 26 September-1 October 1998, Athens, Greece, EAAP Publication 95 (pp. 312-315).

Duncan, I. J. H. (2006). The changing concept of animal sentience. Applied Animal Behaviour Science, $100(1-2), 11-19$.

EFSA. (2006). The risks of poor welfare in intensive calf farming systems. An update of the Scientific Veterinary Committee Report on the welfare of calves. EFSA Journal, 366, 1-36.

Fraser, D., Weary, D. M., Pajor, E. A., \& Milligan, B. N. (1997). A scientific conception of animal welfare that reflects ethical concerns. Animal Welfare, 6(3), 187-205.

Gasteiner, J., \& Hochsteiner, W. (2001). Skin lesions in tied and free dairy cows. Bautagung Gumpenstein 2001, 43-48. https://www.raumberg-gumpenstein.at/cm4/de/forschung/publikationen/ downloadsveranstaltungen/viewdownload/90-bautagung-2001/303-aufstallungsschaedenanbindehaltung-gasteiner.html. Accessed December 21, 2017 (in German).

Gavojdian, D., Cziszter, L. T., Acatincăi, S., Tripon, I., Baul, S., Ciobanu, A., et al. (2009). Researches regarding resting behaviour in lactating dairy cows during first hundred days after calving. Lucrăriştiinţifice Zootehnieşi Biotehnologii, 42(2), 564-567. 
Gudev, D., Popova-Ralcheva, S., Yanchev, I., \& Moneva, P. (2007). Adrenal response to stress and plasma level of cholesterol, urea and indol in acetylsalicylic acid treated lambs. Bulgarian Journal of Agriculural Science, 13, 575-581.

Gutzmirtl, D. (2008). Influence of accommodation and housing of sows on production, health and welfare indicators. Doctoral thesis, Faculty of Veterinary Medicine, University of Zagreb, Zagreb, Croatia (in Croatian).

Hammond Seaman, A. (2014). Overview of the WBVN and future plan. In 1st Western Balkan regional meeting of animal welfare experts, 27-28 February 2014, Tuheljske Toplice, Croatia. http://wbvn. net/wp-content/uploads/2014/03/zagreb-CVI-RSPCA.pdf. Accessed December 4, 2017.

Harrison, R. (1964). Animal machines: the new factory farming industry. London: Vincent Stuart Publishers.

Hristov, S. (1989). A study of parameters of importance for the assessment of adaptation newborn calves in the intensive production. Master thesis, Faculty of Veterinary Medicine, University of Belgrade, Belgrade, Serbia (in Serbian).

Hristov, S., Anojčić, B., Prenkić-Hristov, M., Todorović, M., \& Bokan, Lj. (1996). The concentration of cortisol in the blood serum of fattening pigs with and without cannibalism symptoms. Veterinarski glasnik, 50(9/10), 1113-1119.

Hristov, S., Đurđević, Đ., Grubić, G., Bogdanović, V., Vidić, R., \& Bokan, Lj. (1994). Cortisol concentration in the blood serum of cattle. Veterinarski glasnik, 48(10), 853-859.

Hristov, S., Stanković, B., Zlatanović, Z., Joksimović Todorović, M., \& Davidović, V. (2008). Rearing conditions, health and welfare of dairy cows. Biotechnology in Animal Husbandry, 24(1-2), 25-35.

Hristovski, M., \& Cvetkovic, A. (2005). Causes and consequences of stressful conditions in the extensive breeding of fish in warm-water fisheries. Macedonian fishery magazine, 8-9, 44-48. (in Macedonian).

Jurkovich, V., Fóris, B., Végh, Á., Kovács, P., Könyves, L., \& Brydl, E. (2012). Assessing welfare quality in Hungarian dairy cattle herds. Magyar Állatorvosok Lapja, 134(10), 605-613. (in Hungarian).

Kirchner, M. K., Košt'ál, L., Bilčík, B., \& Winckler, C. (2017). Mapping farm animal welfare research in an enlarged Europe: International collaboration, bibliometric output, research resources and relation to economic indices. Scientometrics, 113(2), 909-922.

Kirchner, M. K., Schulze Westerath, H., Knierim, U., Tessitore, E., Cozzi, G., Pfeiffer, C., et al. (2014). Application of the Welfare Quality ${ }^{\circledR}$ assessment system on European beef bull farms. Animal, 8(5), 827-835.

Kovačević, S. (1981). Behavior and recognition of non-laying hens. Master's thesis. Faculty of Veterinary Medicine, University of Zagreb, Zagreb, Croatia (in Croatian).

Kovács, L., Bakony, M., Tőzsér, J., \& Jurkovich, V. (2013). Changes in heart rate variability of dairy cows during conventional milking with nonvoluntary exit. Journal of Dairy Science, 96(12), 7743-7747.

Kovács, L., Kézér, F. L., Jurkovich, V., Kulcsár-Huszenicza, M., \& Tőzsér, J. (2015). Heart rate variability as an indicator of chronic stress caused by lameness in dairy cows. PLoS ONE, 10(8), $1-13$.

Kovács, L., Tőzsér, J., Szenci, O., Póti, P., Kézér, F. L., Ruff, F., et al. (2014). Cardiac responses to palpation per rectum in lactating and nonlactating dairy cows. Journal of Dairy Science, 97(11), 6955-6963.

Lund, V., Coleman, G., Gunnarsson, S., Appleby, M. C., \& Karkinen, K. (2006). Animal welfare science: Working at the interface between the natural and social sciences. Applied Animal Behaviour Science, 97(1), 37-49.

Madjirov, Z. (1981). Occurrence and prevention of stress in intensive pig production. Socialist Agriculture, 1(2), 64. (in Macedonian).

Madjirov, Z., \& Tokovski, T. (1984). The impact of stress on the production and reproduction domestic animals. Macedonian Veterinary Review, 18(2), 24-30. (in Macedonian).

Matković, K., Vučemilo, M., \& Matković, S. (2007). Influence of alternative layer hens housing systems on eggs quality. Meso, 9(1-2), 47-51. (in Croatian).

Millman, S. T., Duncan, I. J. H., Stauffacher, M., \& Stookey, J. M. (2004). The impact of applied ethologists and the International Society for Applied Ethology in improving animal welfare. Applied Animal Behaviour Science, 86(3-4), 299-311.

Nikolov, V. (2005). Nutrition behaviour of cows at free access to alfalfa hay and restricted access to green maize. In Book of proceedings of the 4th international congress on ethology in animal production, 19-21 October 2005, Nitra, Slovakia (pp. 134-143). 
Ofner, E., Amon, T., Lins, M., \& Amon, B. (2003). Correlations between the results of animal welfare assessments by the TGI 35 L Austrian Animal Needs Index and health and behavioural parameters of cattle. Animal Welfare, 12(4), 571-578.

Ostović, M. (2012). The effect of rubber flooring in service unit on gilt welfare. Doctoral thesis, Faculty of Veterinary Medicine, University of Zagreb, Zagreb, Croatia (in Croatian).

Ostović, M., Pavičić, Ž., Tofant, A., Balenović, T., Ekert Kabalin, A., \& Menčik, S. (2009). Welfare of turkeys in intensive production. Stočarstvo, 63(2), 49-55. (in Croatian).

Pavičić, Ž. (1997). The behaviour of gilts and level of cortisol in blood, after changes in keeping and housing. Doctoral thesis, Faculty of Veterinary Medicine, University of Zagreb, Zagreb, Croatia (in Croatian).

Petak, I. (2006). The effect of Ascogen ${ }^{\circledR}$ and Baypamun ${ }^{\circledR}$ on boars' behaviour and welfare in summer period. Doctoral thesis, Faculty of Veterinary Medicine, University of Zagreb, Zagreb, Croatia (in Croatian).

Petkova, P., \& Hammond Seaman, A. (2017). Overview of RAWC activities. In 3rd Western Balkan regional meeting of animal welfare experts, 22-23 March 2017, Bled, Slovenia. http://rawc.eu/wpcontent/uploads/2017/03/1.-Overview-of-RAWC-activities-Alexandra-Hammond-Seaman.pdf. Accessed November 17, 2017.

Popescu, S., Diugan, E. A., \& El Mahdy, C. I. (2012). Physiological indicators in the welfare assessment of riding horses. Animal Science and Biotechnologies, 45(2), 256-262.

Popescu, S., El Mahdy, C., Diugan, E., Borda, C., \& Sandru, C. D. (2011). Welfare assessment of dairy cows at farm level. Bulletin of University of Agricultural Sciences and Veterinary Medicine ClujNapoca. Veterinary Medicine, 68(1), 295-302.

Princz, Z., Radnai, I., Biró-Németh, E., Matics, Zs, Gerencsér, Zs, Nagy, I., et al. (2008). Effect of cage height on the welfare of growing rabbits. Applied Animal Behaviour Science, 114(1-2), 284-295.

Radeski, M., \& Ilieski, V. (2014). Usage of tri-axial acceleration of the hindleg for recognizing sheep behaviour. In Book of abstracts of the 65th annual meeting of the European federation of animal science (EAAP), 25-28 August 2014, Copenhagen, Denmark (p. 98).

Radeski, M., Janevski, A., Ratkova, M., Angelovski, L. J., \& Ilieski, V. (2014). Welfare assessment and main concerns in dairy farms in Macedonia. In Proceedings of the 5th international scientific meeting days of Veterinary medicine, 5-7 September 2014, Ohrid, Macedonia.

Radeski, M., Mikuš, T., Zupan, M., Nenadović, K., Ostović, M., Jurkovich, V., et al. (2016). Animal welfare research in the last three decades in the Danube region: A bibliographic study. In Proceedings of the 50th congress of the international society for applied ethology, 12-15 July 2016, Edinburgh, United Kingdom (p. 120).

Relić, R. R., Hristov, S. V., Vučinić, M. M., Poleksić, V. D., \& Marković, Z. Z. (2010). Principles of fish welfare assessment in farm rearing conditions. Journal of Agricultural Sciences, 55(3), 273-282.

Report, Brambell. (1965). Report of the Technical Committee to enquire into the welfare of animals kept under intensive livestock husbandry systems. London: Her Majesty's Stationery Office.

Šamanc, H., Šarac, M., Sinovec, Z., \& Vujanac, I. (2006). Prolonged starvation and weight loss in sows. In Proceedings of 6th symposium "Breeding and protection of pig health", 3-5 May, Vršac, Serbia (pp. 115-121).

Šamanc, H., Stojić, V., Adamović, M., Kirovski, D., Stojanović, B. (2007a). Care, nutrition, posture, and health status of calves. In Proceedings of 5th Symposium "Feeding, reproduction and protection of cattle health”, 4-7 July, Banja Kanjiža, Serbia (pp. 3-21).

Šamanc, H., Vujanac, I., Dimitrijević, B., Kirovski, D., Pudlo, P., Milovanović, A., et al. (2007b). The body condition of Holstein cows in various stages of production: Reproductive cycle. In Proceedings of 5th symposium "feeding, reproduction and protection of cattle health", 4-7 July, Banja Kanjiža, Serbia (pp. 3-21).

Sandøe, P., Christiansen, S. B., Appleby, M. C., Webster, A. J. F., \& Main, D. C. J. (2003). Farm animal welfare: The interaction of ethical questions and animal welfare science. Animal Welfare, 12(4), 469-478.

Šarac, M. (1991). A study of weight loss syndrome in farrowing sows. Graduation thesis, Faculty of Veterinary Medicine, University of Belgrade, Belgrade, Serbia (in Serbian).

Szendrő, Z. S., Mikó, A., Odermatt, M., Gerencsér, Z., Radnai, I., Dezséry, B., et al. (2013). Comparison of performance and welfare of single-caged and group-housed rabbit does. Animal, 7(3), 463-468.

Veljačić, M., \& Tofant, A. (2009). Farming and welfare of the aquatic organismes. In Book of abstracts of the 16th international conference Krmiva, 1-3 June 2009, Opatija, Croatia (pp. 99-100). 
Vučemilo, M., Matković, K., Štoković, I., Kovačević, S., \& Benić, M. (2012). Welfare assessment of dairy cows housed in a tie-stall system. Mljekarstvo, 62(1), 62-67.

Waiblinger, S., Graml, C., Nordmann, E., Mersmann, D., \& Schmied-Wagner, C. (2014). On farm welfare assessment in dairy goat farms. In Proceedings of the 6th international conference on the assessment of animal welfare at farm and group level, 3-5 September 2014, Clermont-Ferrand, France (p. 96).

Waiblinger, S., Knierim, U., \& Winckler, C. (2001). Development of an on-farm welfare assessment system in dairy cows using an epidemiological approach. International Workshop on Assessment of Animal Welfare at Farm or Group Level, Kopenhagen, Denmark. Acta Agriculturae Scandinavica, Section A: Animal Science, 51(Suppl. 30), 73-77.

Wemelsfelder, F., \& Mullan, S. (2014). Applying ethological and health indicators to practical animal welfare assessment. Revue Scientifique Et Technique-Office International Des Epizooties, 33(1), 111-120.

Whay, H. R., Main, D. C. J., Green, L. E., \& Webster, A. J. F. (2003). Animal-based measures for the assessment of welfare state of dairy cattle, pigs and laying hens: Consensus of expert opinion. Animal Welfare, 12(2), 205-217.

Winckler, C., Capdeville, J., Gebresenbet, G., Hörning, B., Roiha, U., Tosi, M., et al. (2003). Selection of parameters for on-farm welfare assessment protocols in cattle and buffalo. Animal Welfare, 12(4), 619-624.

Zaludik, K., Lugmair, A., Baumung, R., Troxler, J., \& Niebuhr, K. (2007). Results of the Animal Needs Index (ANI-35 L) compared to data regarding feather damage and injuries in free-range and organic laying hen flocks in Austria. Animal Welfare, 16(2), 217-219.

Zupan, M., Berk, J., Wolf-Reuter, M., \& Štuhec, I. (2003). Broiler behaviour in three different housing systems. Landbauforschung Völkenrode, 55(2), 91-97. 